International Journal of Child, Youth and Family Studies (2015) 6(2): 308-327

\title{
HEALTH IMPACT ASSESSMENT, MUNICIPAL DEVELOPMENT PRACTICES, AND CHILDREN'S HEALTH
}

\section{Robert Rattle}

\begin{abstract}
Public policies can have a considerable effect on health outcomes. All too often, however, public policy and health are debated at a national level, creating a disconnect between local politics and actionable and meaningful health outcomes. This article draws on the results of a retroactive policy Health Impact Assessment (HIA) of a new hospital siting exercise to illustrate how local municipal policies can affect the social determinants of health. It will highlight and discuss results for the health of children. These results show that children's health is differentially affected across the new host (urban sprawl) and old host (downtown) neighbourhoods. A number of adverse impacts resulting from the shift in location and related development patterns have been generated across the city. Despite the direct relevance to the health sector and the significant control local authorities had over the development processes, development decisions and existing frameworks played a central role in a less than optimal result for children's health. Means of mitigating these effects and recommendations for future development are briefly considered.
\end{abstract}

Keywords: health impact assessment, urban development, hospitals/health care services, child health, noise pollution

Robert Rattle, BSc, is an independent researcher and consultant, and Executive Director of the Crane Institute for Sustainability, 736A Queen Street East, Sault Ste. Marie Ontario, P6A 2A9. Email: robert14robert@yahoo.ca 
International Journal of Child, Youth and Family Studies (2015) 6(2): 308-327

The social determinants of health (SDH) are the social and economic conditions that determine the health of populations (World Health Organization [WHO], 2008). These conditions are largely laid down by public policies, making public policy an important driver of health outcomes. The living environments that children encounter derive from these conditions and "form a critical foundation for their entire lifecourse" (Irwin, Siddiqui, \& Hertzman, 2007, p. 7). The health care systems, social and cultural environments, physical environments and built form, emotional support structures and cognitive domains that children encounter will influence learning abilities and outcomes, economic and social participation, and general well-being throughout their entire lives.

Anchor institutions comprise significant public infrastructure facilities and produce considerable social, economic, and health impacts through the community structures and networks they establish. Universities and hospitals are two of the largest such anchor institutions. Hospitals can produce both beneficial and adverse impacts on both their host communities and the wider community or municipality. In addition to serving health care needs, hospitals can directly serve employment, economic, educational, social development and cohesion, long-term care, disaster relief, and other community purposes. Indirectly, such institutions can affect the broader determinants of community health. Their siting and operational features are key urban design and engineering factors that must meet local municipal bylaws, provincial regulations, and federal requirements. As such, hospitals can affect access to recreational and leisure services, mobility and transportation, health care facilities and services, and community design and wellbeing. In so doing, hospitals play an important role in the social and environmental conditions of communities and their health determinants.

These conditions will have far-reaching and diverse consequences for children's health. Urban design, mobility options, and transportation choices will: affect road safety and build mobility expectations well into the future; produce recreational opportunities and affect physical skills and fitness levels; facilitate early child development; and define access to health care. Children's health is also affected by family and community conditions. Family and community opportunities such as social and economic conditions, emotional and psychological supports, and community cohesion may be influenced by the nature and characteristics of major anchor institutional developments.

The built environment is an important factor in health. Research suggests the built environment can contribute to human health outcomes such as respiratory and cardiovascular health, injuries, physical fitness, obesity, mental health, and social capital (Bray, Vakil, Elliott, \& Abelsohn, 2005; Frank, 2004; Lee \& Rubin, 2007). In addition, the built environment can have significant impacts on vulnerable populations such as children, including their perceptions of and future life opportunities, skills development, educational outcomes, and health practices and coping skills (WHO, 2009b).

A major anchor institution such as a hospital will produce consequences for the built environment due to the nature of its physical footprint and development activity, including the natural environmental characteristics such as forest and ground covers, drainage and flood patterns; roads and sewers, water and wastewater infrastructure; traffic and road infrastructure 
International Journal of Child, Youth and Family Studies (2015) 6(2): 308-327

along with public transit routes and frequencies, pedestrian and cycling facilities; and noise, and air quality. In addition, major facilities often invoke community-wide urban design and development activities, shifting, altering or transforming market values, well-being, and community cohesion across an entire community.

In 2004, the Government of Ontario provided funding through Infrastructure Ontario and the North East Local Health Integration Network (NELHIN) for the construction of a new private-public partnership (P3) hospital facility in the city of Sault Ste. Marie. During the development stages of the new Sault Area Hospital (SAH), discussions were initiated on the design and location of the new facility. Primary information provided to the public suggested two options: reconstruction of a new facility at the current downtown site or a new facility at a new site. The final decision was to construct a new facility on a new site distant from both the downtown core and existing hospital site.

The process to develop the new SAH required considerable input from the municipality in terms of urban design and development processes, bylaws and official plan amendments, and local authority input. In addition, the facility was required to satisfy provincial mandates (e.g., Ministry of Environment - now Ministry of Environment and Climate Change - noise legislation) and federal requirements and guidelines (e.g., Transport Canada helipad design configuration).

Despite these existing requirements, very little community input (beyond fundraising) or dialogue was undertaken by local authorities or at the political level. In contrast, impact assessment and Health Impact Assessment (HIA) processes stress the importance of early and meaningful dialogue with all stakeholders (Sinclair \& Diduck, 2009; National Collaborating Centre for Healthy Public Policy [NCCHPP], 2012).

Following the construction of the new hospital, it became evident a number of adverse impacts had occurred. A rapid desk-based retroactive Health Impact Assessment (HIA) was conducted, supplemented by the Ministry of Health and Long Term Care's (MOHLTC) Health Equity Impact Assessment (HEIA) Toolkit to identify and evaluate impacts and suggest possible means of mitigating these impacts, as well as to inform policy and programme development for future anchor institutions of a similar nature.

\section{Health Impact Assessment}

HIA and HEIA are important tools that can help decision-makers reduce the short- and long-term costs of policy, programme and project decisions. They help to ensure activities are undertaken in fair, equitable, sustainable and healthy ways that improve the health and well being of diverse populations and avoid or minimise adverse and unintended impacts of those activities.

HIA is a practice to make visible the interests of public health in decision-making. The World Health Organization (1999) defines HIA as "a combination of procedures, methods, and tools by which a policy, program, or project may be judged as to its potential effects on the health of a population, and the distribution of those effects within the population” (p. 4). 
International Journal of Child, Youth and Family Studies (2015) 6(2): 308-327

Four values are integral to HIA: democracy, equity, sustainable development, and the ethical use of evidence that emphasizes a rigorous structured analysis based on scientific disciplines and methodologies.

While available guidance documents for HIA describe the procedural steps and products of each stage of the HIA process, there exists considerable diversity in the practice and products of HIA due to the variety of decisions assessed, diverse practice settings, and the nascent evolution of the field (Pew Charitable Trusts, 2014). In general, the steps of a HIA include screening, scoping, assessment, reporting, and monitoring. Key impact characteristics and impact assessment considerations are listed in Table 1.

Table 1

Key Impact Characteristics Considered by a Health Impact Assessment

\begin{tabular}{|l|l|l|l|l|l|l|}
\hline \multicolumn{1}{|c|}{$\begin{array}{c}\text { Nature of } \\
\text { impact }\end{array}$} & $\begin{array}{c}\text { Temporal } \\
\text { characteristics }\end{array}$ & Magnitude & $\begin{array}{l}\text { Direction of } \\
\text { change in the } \\
\text { affected } \\
\text { environmental } \\
\text { parameter }\end{array}$ & $\begin{array}{l}\text { Spatial } \\
\text { extent }\end{array}$ & $\begin{array}{l}\text { Reversibility } \\
\text { of change of } \\
\text { the affected } \\
\text { environment } \\
\text { al parameter }\end{array}$ & $\begin{array}{c}\text { Probability } \\
\text { of } \\
\text { occurrence }\end{array}$ \\
\hline $\begin{array}{l}\text { Incremental } \\
\text { Additive } \\
\text { Synergistic } \\
\text { Antagonistic }\end{array}$ & $\begin{array}{l}\text { Duration } \\
\text { Immediacy } \\
\text { Frequency } \\
\text { Regularity }\end{array}$ & $\begin{array}{l}\text { Size } \\
\text { Degree } \\
\text { Concentration }\end{array}$ & $\begin{array}{l}\text { Increasing } \\
\text { Decreasing } \\
\text { Positive } \\
\text { Negative }\end{array}$ & $\begin{array}{l}\text { On-site } \\
\text { Off-site } \\
\text { Regional } \\
\text { Global }\end{array}$ & Reversible \\
Irreversible & Likelihood \\
Risk & & & & \\
\hline
\end{tabular}

Source: Noble (2010).

The project method utilised a rapid desk-based HIA within a framework and template reflective of all health determinants contained in the MOHLTC's HEIA toolkit. The assessment had its focus on the municipal development processes related to the new hospital. While the assessment area focused on the local neighbourhood of the new SAH site, the study assessment was bounded by the entire community of Sault Ste. Marie. The assessment did not consider the medical operations of the facility, the management and internal activities of the facility, the interior design and construction, or other internal operations of the facility or the health care services it provides. This paper distills the main elements relevant to the political economy of children's health, specifically how certain public policy sectors affect the health of children during the municipal development processes undertaken for the hospital facility.

\section{Health Impact Assessment of the new Sault Area Hospital}

The identified impacts differentially affect populations across the municipality. The immediate community around the new SAH benefits from local health care and improved access to a growing number of health care services. But, residents and those who attend school, work, and recreate in the area must confront the realities of increased traffic, air pollution, noise, and 
stresses and reduced safety and green spaces, despite a marginal improvement in walkability and cycling infrastructure. Simultaneously, the downtown area, previously host to the Sault Area Hospital, now experiences the economic and social impacts resulting from the loss of a major anchor institution along with reduced access to many health care services and facilities, despite the potential for reduced traffic flows and less 24-hour noise.

In the area of the new site, new developments include major retail establishments, tourist amenities, educational and health care facilities, a major renewable energy site, and residential developments. In addition, extensive transportation network expansions and new construction has been undertaken. Figure 1 illustrates the new site and related development activity. The associated increased traffic volumes and related development have introduced new health risks for children resulting from higher levels of traffic-related pollution and reduced road traffic safety.

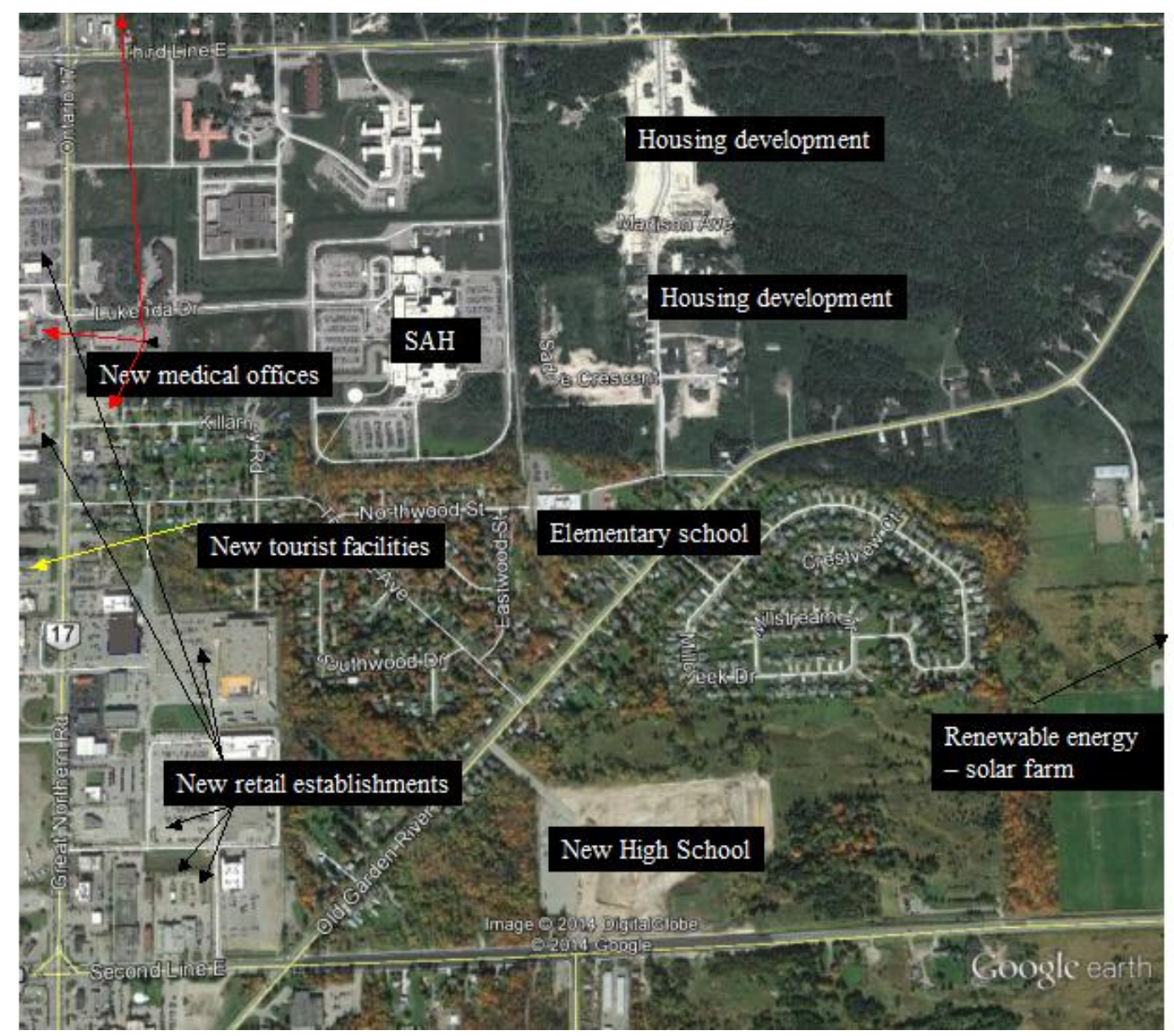

Figure 1. New site of the Sault Area Hospital and surrounding neighbourhood.

Increased noise from a new helicopter landing pad and overnight activity has negatively affected sleep patterns and school learning, and affected family socio-economic opportunities and social engagement. An increased number of smokers and hospital-related drug paraphernalia in the area of the school and a significant loss of forested and natural spaces have raised health 
International Journal of Child, Youth and Family Studies (2015) 6(2): 308-327

challenges for children and function to militate against smoking reduction policies and programmes. With the loss of such a significant anchor institution in the downtown core, access differentials to health services have emerged across the municipality. Relocating from a central downtown location accompanied by a shift in many health care services to the new location has further isolated a key population segment with limited transportation, time, and financial resources from effective access to health care facilities.

The balance of this section will discuss details of the results of the HIA relevant for children's health from traffic and noise impacts, and provide a brief overview of impacts on children's health from changes in air quality, natural spaces, and socio-economic status.

\section{Traffic}

Traffic can generate a significant source of noise, air pollution, safety risks, and loss of community cohesion. Children in particular are adversely affected by traffic and traffic patterns in a variety of ways. The new SAH site has had a considerable influence on municipal development and subsequently traffic patterns and volumes, especially in the immediate area of the new site.

Once the new site location was announced, an urgent need to increase roadway capacity in the site study area was identified as a municipal priority. Roadway expansion encourages a greater volume of vehicles, producing as a consequence a number of adverse health impacts to which children are especially vulnerable. As illustrated in Figure 1, road expansion activities include extending Pine Street, Sackville Road, and Third Line. In addition, Great Northern Road has been resurfaced and Second and Third Lines have been widened. Studies are also underway to expand the capacities of Third Line East and Black Road.

Development activities also include a new high school, with roadway access to the neighbourhood community. In part to facilitate higher traffic volumes associated with development in the area (school, hospital, commercial, etc.), local neighbourhood streets have been resurfaced. This has the potential to invite higher speeds and increased injuries for pedestrians as the roadway cross-sections were not upgraded at the times of resurfacing (and remain so) despite community requests for sidewalks and traffic calming infrastructure. Since these roadways are the primary routes for children travelling to and from school and moving about the neighbourhood, the children must now compete with increasing traffic volumes and speeds on streets that do not have sidewalks or grade-separated routes for pedestrians.

In addition to increased safety risks for children travelling and at play, higher traffic volumes overall throughout the study area have led to increased air pollution. This will be briefly discussed below. Traffic is also a considerable source of noise (also discussed below).

The municipality has reasoned that there is no new traffic generated and, in effect, traffic has merely shifted from the downtown core of the previous hospital site to the areas around the new SAH site. In part, this is true, in that there has indeed been a shift in traffic. However it is an incomplete picture. Significant additional trips, extra distances, higher speeds, and increased volumes are likely to have been generated due to the urban sprawl nature of the new site, wider 
International Journal of Child, Youth and Family Studies (2015) 6(2): 308-327

roads with higher posted speed limits, additional commercial development outside the urban service boundary surrounding the new site (including that directly and indirectly related to the $\mathrm{SAH}$, such as medical offices and health care services), and significant additional residential developments occurring adjacent to the new hospital site outside the municipal service boundary. Public transport, while expanded to service the SAH, is significantly less effective as population density is considerably lower at the new site than in the downtown core. Pedestrian and cycling access to the new site and in the local area is considerably less effective or appealing. In addition, access to off-site resources and amenities, such as restaurants and shops, are much less accessible in a much more hostile environment to people-centred mobility. Accordingly, there are far more vehicle trips made by employees and staff of the SAH to access these services than at the previous site.

Not only does excess traffic and auto-dependency generate considerable health concerns for children from the pollution and safety aspects, it also generates a perception of normalisation of mobility being closely linked with a sedentary lifestyle. Furthermore, it also associates that level of normalisation with a certain level of expectations of material acquisition that, in addition to sedentarianism, creates a powerful incentive for economic instability. These factors reinforce lifelong and early childhood experiences which can lead to cardiovascular disease, obesity, asthma, and other chronic non-communicable diseases later in life.

\section{Noise}

Noise is often defined as an unpleasant or annoying nuisance that affects auditory sensation and can be harmful to health (e.g., NCCHPP, 2014; Health Canada, 2005). However, as Dr. William H. Stewart, former U.S. Surgeon General observed, referring to noise as a nuisance is like calling smog an inconvenience (Environmental Protection Agency [EPA], 1978, p. 25).

Noise is generally defined as unwanted sound (Hammer, Swinburn, \& Neitzel, 2014; European Agency for Safety and Health at Work, n.d.). Noise, however, is a far greater health risk than a mere "nuisance" might imply. Noise can produce significant adverse health impacts including stress, sleep disorders, increased heart rate, raised blood pressure, and cardiovascular disease. There have been numerous studies that correlate a variety of physiological effects with excess noise (Frankenhaeuser, 1974; Henkin, 1963; Rosenberg, 1991). These can lead to increased releases of stress hormones, increased blood pressure, and increased muscle spasms. Exposure to moderate levels of noise may also induce psychological disorders including stress, annoyance, irritability, and intellectual function impairment and interference with the execution of complex tasks. Intense levels of noise can cause personality changes and aggressive responses, reduced coping abilities, sleep disturbances, and changes in mental health (Kam, Kam, \& Thompson, 1994; Kujala \& Brattico, 2009).

Noise activates the body's sympathetic nervous system to raise blood pressure and heart rate (Haralabidis et al., 2008). While residents may indicate they have become used to noise or are able to "tune it out", that habituation does not seem to extend to the cardiovascular system during night time exposures (Muzet, 2002). Sleep disruption is associated with increased lipid and cortisol levels, raising risks of depression and atherosclerosis (Meerlo, Sgoifo, \& Suchecki, 
International Journal of Child, Youth and Family Studies (2015) 6(2): 308-327

2008; Hoffman et al., 2013). Large-scale studies have identified an association between aircraft noise exposure and increased hospital admissions for cardiovascular diseases (Correia, Peters, Levy, Melly, \& Dominici, 2013; Hansell et al., 2013). Residential road traffic noise has been associated with a higher risk of diabetes (Sorensen et al., 2013).

Fatigue, anxiety, mood changes, depression, and reduced performance are typically associated with sleep disorders (Berglund, Lindvall, \& Schwela, 1999; Maynard et al., 2010; WHO, 2009a). In children, sleep disorders can lead to cognitive impairment and learning difficulties (Milette \& Carnevale, 2003; WHO, 2011). Sleep disturbance also has an effect on mood, fatigue, performance, cognitive abilities, vigilance, and can boost epinephrine levels that contribute to stress (Passchier-Vermeer \& Passchier, 2000). Vulnerable groups include the elderly, the sick, children, and shift workers. The maximum sound level should not exceed 45 dBA, similar to a refrigerator, but is ideally around 30 dBA (Alenius, 2001; WHO 2009a).

The WHO (2011) has conservatively estimated that "DALYs lost from environmental noise are 61,000 years for ischaemic heart disease, 45,000 years for cognitive impairment of children, 903,000 years for sleep disturbance, 22,000 years for tinnitus, and 587,000 years for annoyance in the European Union Member States and other western European countries” (p. v). In 1981, the U.S. Environmental Protection Agency (EPA) estimated that nearly 100 million people in the United States had annual exposures to traffic noise that were high enough to be harmful to health (Simpson \& Bruce, 1981).

There are numerous sources of noise directly attributed to the new hospital which have generated concern and complaints from local residents. These include traffic and transportation, including public transit buses both during movement and while idling, parking lots which produce noise from vehicle movements, idling, and security alarms, and on-site activities such as shipping and receiving, property maintenance, and heating, ventilation, and air conditioning equipment. The most significant noise is generated by on-site snow maintenance and related activities (such as spring and summer street sweeping) that operate primarily during the overnight hours, typically beginning at 21:00 and progressing through the night until 06:00 through the months of October until June. In addition, the proximity of the elementary school serves as a reminder of poor planning practices that neglect the adverse impacts from noise that can directly affect children's health. Finally, noise is generated throughout the neighbourhood and especially for perimeter residents from an on-site helicopter pad located 100 meters from the nearest residential dwellings.

By contrast, the old site had one residential dwelling in immediate proximity to most of these noise sources, with the exception of traffic. Parking facilities were located between the hospital and St. Mary's River, with institutional government buildings on the west side and one residential dwelling adjacent to the property on the east. However, the previous site was well serviced by public transit and had excellent pedestrian and cycling access. The helicopter pad was 240 metres from the hospital and 380 metres from the nearest residence while situated adjacent to the St. Mary’s River. Normal flight paths did not disturb residents on a regular basis.

At the new site, these additional sources of noise affect children's health by elevating the background levels of noise, generating interruptive noises, producing sleep disruptions through a 
International Journal of Child, Youth and Family Studies (2015) 6(2): 308-327

substantial portion of the year, and affecting concentration levels in and out of school. Noise also necessarily affects children when it affects the community or family, and the ability and quality of parents' work, social engagement, and community participation. Psychological and emotional distress caused by loss of sleep or increased stress can have deep and profound effects on families and the health of children. These impressions can last throughout a lifetime and manifest as future domestic violence, poverty, and economic performance.

The WHO has identified benchmark levels of $30 \mathrm{dBA}$ for maximum nighttime noise levels. Local residents have measured levels as high as $85 \mathrm{dBA}$ overnight for snow clearing. In comparison, levels of a hydraulic jackhammer measured $71 \mathrm{dBA}$ on the same tools and scale, at a much closer distance. At point of impingement, the helicopter measures only slightly above snow clearing machinery, at $86 \mathrm{dBA}$. Of importance, snow clearing and maintenance activities operate throughout the night for most of the year. However, measures of sound pressure alone are a poor indicator of noise disturbance. As noted above in Table 1, the duration, continuity, immediacy, frequency, and regularity of noise can contribute to adversely impact human health. For example, whereas certain high frequency sounds may be attenuated with sufficient building techniques and sound barriers, heavy vehicles (snow removal machinery, trucks or buses idling, front-end loaders operating, etc.) generate considerable low frequency noises and vibrations that can transmit through ground substrate and into building foundations, amplifying noise and vibrations within residential dwellings.

Children are especially vulnerable to adverse noise for a number of reasons. First, their perceptions of noise are different from adults and many children are unable to comprehend and recognise dangerous exposure levels, as in the case of helicopter landings and takeoffs, for example. Children are also less able to effectively react and respond to noises - they are unable to identify and avoid sources of noise. Noise can also interfere with the communication of danger or dangerous situations, and noises can interfere with learning and concentration. Children may also be more at risk for noise due to their behaviour such as use of electronic devices or playing outside where noise sources may be present. Finally, children are less likely to identify sleep disruptions as the source of their adverse health impacts, and convey such information to parents or guardians for mitigating action. Compounded by a parents' sleep loss, domestic, economic, and educational stress can rapidly escalate.

These and other factors can place children at an increased risk of long-term adverse health outcomes through such pathways as the lifelong impairment of learning and education, short-term deficit followed by adaptation and non-intentional lesions (WHO, n.d.). The result can be indirect such as through long-term physiological and psychological impacts, direct such as noise-induced hearing loss and threshold shifts, and impaired cognition.

Exposure to sudden or unexpected noise can induce a startle reaction with stress responses and can lead to non-intentional injuries. For example, the sudden blast of an ambulance siren may cause a child to leap before looking, resulting in a potential traffic injury especially where road and pedestrian traffic is not grade separated or does not otherwise incorporate human-centred design. Chronic noise exposure can impair cognitive function, reading comprehension, and long-term memory (Evans, 1993; Maxwell \& Evans, 2000; Wachs, 1982; Yang \& Bradley, 2009). The effects of noise can be different for different age groups, 
International Journal of Child, Youth and Family Studies (2015) 6(2): 308-327

length of exposure and other factors (Brandon, 2008; Milette \& Carnevalle, 2003).

In addition, children become especially susceptible to noise when family and community noise-derived impacts affect the social, economic, and cultural backgrounds of their environments. Loss of income or economic security by parents, for instance, can generate a considerable adverse affect on children's health, which can be long-lasting into their future.

The P3 arrangement further complicates matters. A transnational corporation has been contracted through the provincial government to manage site operational aspects for an extended period. This arrangement exposes the community to the challenges inherent in outsourcing the role of the state in health care provisions, making implementation of its responsibilities as guarantor of health rights responsibilities more difficult (Chapman, 2014). The P3 approach to fiscal management is a provincial policy for health care facilities. Despite the lack of financial incentive for the SAH to invest in capital or operational expenditures to reduce the burden of disease associated with certain noises, the private member of the P3 partnership responsible for maintaining the facility has even less incentive to do so.

An additional complicating factor was the lack of incentive for any substantive discourse with the community. In Ontario the Environmental Impact Assessment (EIA) process does not extend to private development proposals, although there are provisions should the developer choose to undertake an EIA, or if the Minister believes there to be reasonable public concern. The lack of community discourse effectively thwarted public engagement to identify possible issues. EIA provisions in Ontario to include private proposals would strengthen health outcomes.

Noise in Ontario largely falls under municipal jurisdiction. In the case of Sault Ste. Marie, an antiquated noise bylaw regulates noises with specific exemptions for snow clearing activities. These bylaws predate the widespread use of heavy machinery for clearing of private parking spaces and the co-locating of mixed urban development zones. The existing bylaws also target activities rather than noise (thus the exemption for snow clearing), leave enforcement and interpretation in the hands of local police services, and maintain the existing quiet zone as outlined around the old hospital site (now sold to developers). Moreover, the bylaw makes little reference to ambient noise levels from traffic and mobile sources with the exception of idling engines in excess of five minutes under liberal conditions. While legal services have been working on an updated noise bylaw, no public discourse has been undertaken, no proposed draft yet exists, and no interim provisions have been offered despite over four years of efforts and numerous public petitions for an improved bylaw.

The province also regulates noises under the Ministry of the Environment and Climate Change; however, there are explicit exclusions for mobile noises as these are left to municipalities to regulate.

Similarly, Transport Canada regulates heliports. Despite requirements to include consultations with the municipality, in the case of the SAH helicopter pad, the level of consultations seem to have been limited to a request to the building division for a building permit. Unfortunately, Transport Canada does not define "consultations" in the legislation. An assessment of the health impacts resulting from the requested location of the helicopter pad was 
International Journal of Child, Youth and Family Studies (2015) 6(2): 308-327

left to the building division to evaluate, which clearly falls well beyond their expertise, interest or, arguably, jurisdiction.

The Leadership in Energy and Environment Design (LEED) "recommends standards to enhance buildings and is based on scores to improve sustainability. LEED standards incorporate American National Standards Institute recommendations regarding background noise and encourage sound- absorptive finishes to limit reverberation in schools. Improvements in construction materials, siting considerations (e.g., siting sensitive structures such as homes and schools well away from noise sources such as high traffic roads and hospitals), and design can have a dramatic impact on noise levels inside buildings - and improve the occupants' quality of life in the process ” (United States Green Building Council [USGBC], 2008).

While there are important elements of urban design (such as traffic noise, locating institutions such as hospitals separate from residential areas and schools), Holzman (2014) notes that professionals "studying community noise highlight the need for controlling noise at the source” (p. A58), suggesting it is important to provide a quiet community environment rather than simply separate people and noise. Other experts note that distancing houses from noise and pollution from vehicle exposures and reducing air pollution by reducing stop-and-go traffic may actually increase noise since traffic may then travel faster producing more noise. Unless carefully planned, the result may merely exchange one health risk for another.

The result has been adverse impacts on children's health through interrupted and poor sleep patterns, co-location of an elementary school exposed to considerable noises, and parental and community socio-economic impacts.

\section{Air Quality}

As the SAH is now located in a more remote location which depends increasingly on personal automobility, many who may previously have walked or taken public transit are much more likely required to drive to access health care facilities. In addition to a more remote location, the poor urban design of the area makes healthy transportation modes far more difficult to engage in the area, exacerbating the problem of automobility. As children under 16 are not allowed to drive in Ontario, this segment is especially isolated and dependent upon public transit or parents to access the new facilities. In addition, patient, employee, staff and contractor access is characterised by private vehicle use. An air ambulance helicopter pad is also located on-site compounding local air pollution. Moreover, the designated flight paths, which may be deviated from at a pilot's discretion, pass directly over many residential houses and properties and in very close proximity to the elementary school (see pad location and flight path in Figure 1). Limited to no data exist on the long-term health effects of jet fuel nor on the soil contamination from jet fuel in urban landing pad locations, exposures of populations on low flight activities of helicopters, and health impacts from residential agricultural and food growing practices from aviation fuels. However, existing data on the health impacts of aviation fuel and children living near airports suggests an adverse health outcome for a variety of diseases (Sheer \& Moss, 2012).

Some of the health effects of repeated exposure to lead include damage to the central nervous system, kidneys and red blood cells, and decreased function in the cardiovascular and 
International Journal of Child, Youth and Family Studies (2015) 6(2): 308-327

immune systems. Lower IQ levels and learning disabilities can also result from lead exposure, especially in children, whose young bodies are more sensitive than those of adults. And scientists at the National Toxicology Program (2010) have concluded that lead and lead compounds are "reasonably anticipated to be human carcinogens". While aviation fuel and that used by Ornge (the air ambulance service of Ontario) is likely different, the health impacts of a petrochemical exhaust fumes accumulating over a neighbourhood from low elevation flights, landings, and takeoffs is likely adverse. Staff and students have noted odours inside classrooms when the fresh air intake system is operating while the helicopter is in use. Numerous residents have commented on the pungent odours when the helicopter is taking off and landing, whether it passes directly overhead or the wind carries fumes across the neighbourhood.

Furthermore, the increased traffic and much larger parking lots require constant maintenance and, as reflected in the section on noise, this is done with heavy diesel machinery, including dump trucks, front-end loaders, sweepers, and pumper trucks. Diesel emissions are a complex mixture of hazardous particles, gases, and vapours. They contain carbon monoxide (CO), carbon dioxide $\left(\mathrm{CO}^{2}\right)$, oxides of nitrogen $\left(\mathrm{NO}^{\mathrm{x}}\right)$, sulphur dioxide $\left(\mathrm{SO}^{2}\right)$, and volatile organic compounds (VOC), specifically non- methane hydrocarbons, carbonyl compounds such as aldehydes, and polycyclic aromatic hydrocarbons (PAH) (Maybe, MacKinnon, \& Kerr, 2005). Diesel emissions are the source of over 40 toxic air contaminants. Health effects of exposure to diesel emissions range from the immediate to long term, and can include mutagenic and carcinogenic, to eyes, nose, throat, and lung irritations including aggravating chronic health problems and triggering asthma events (Office of Environmental Health Hazard Assessment [OEAHA], n.d.). Health Canada (n.d.) has identified that there is no threshold level below which adverse health effects from exposure to particulate matter (PM) are not observed.

In addition, the increased traffic and construction activity (roads, infrastructure, commercial, and residential developments) in the study area has and continues to generate significant levels of air emissions on an ongoing basis.

Given the proximity to an elementary school and residences, and that children are often outside playing, this has considerably elevated the risks for future adverse health effects for these children in adulthood. The situation is heightened for children in lower socio-economic families as these children are often left unsupervised and more often outside within the neighbourhood, with fewer chances to exercise and recreate in more environmentally friendly environments due to the limited financial and mobility resources available to them and their parents.

\section{Natural Spaces}

Access to natural spaces is beneficial for healthy child development (Children and Nature Network [CNN], 2012). Exposure to a natural environmental setting has been shown to develop richer imagination, increased physical activity, greater focus and a calmer disposition, and positive social interactions in children (Nedovic \& Morrissey, 2013). Access to green spaces has been associated with beneficial outcomes on fetal growth (Dadvand et al., 2012; van den Berg \& van den Berg, 2011). Poor access to green spaces has been associated with behavioural problems in children (Markevycha et al., 2014). 
International Journal of Child, Youth and Family Studies (2015) 6(2): 308-327

The new hospital site required the clearing of 20 acres of natural green space, and the related residential developments each cleared a similar amount of green spaces surrounding the school and local neighbourhood. Those spaces provided refuge for a variety of wildlife and opportunities for learning and natural connections for students. Local residents also used much of this area for walking or skiing, and it served as a natural flood buffer and respite from the stresses of city life. In addition, the natural vegetation served as both a sink for carbon and air pollutants, as well as offering a cooling effect during hot summer days. This has all been replaced with concrete and pavement, adding both to noise, stress and heat island effect, as well as eliminating natural settings and learning opportunities for children and youth. Ironically, negotiations between the city and school board enabled a new recreational trail (negotiated with the city as part of the SAH development) to cross the perimeter of the school property leading to the elimination of additional green space to expand parking spaces at the elementary school. In so doing, the new parking lot severed a recently constructed two-year-old nature trail and outdoor learning centre, eliminating it from possible future use.

\section{Socio-economic Impacts from Related Development}

Hospitals have the potential to negatively impact the quality of life of nearby residents. Hospitals contribute to high traffic volumes that not only congest neighbourhood streets, but also potentially elevate risks for pedestrians and families with children. The background noise of traffic, coupled with emergency sirens, construction projects, on-site activities and helicopters, can also make for noisy neighbourhoods near hospitals. These conditions can drive away some residents, which can lead to lower property values and neighbourhood instability (Beecher, 2007).

Anecdotal information suggests approximately 35 homes went up for sale in the 18 months following the opening of the new SAH. While listing reasons remain largely unknown, numbers, list prices, and selling prices suggest at least some were directly attributable to the new hospital site opening; 35 listings in 18 months compares to approximately one home per year in the same neighbourhood in the previous four years. Regardless of the reasons for these sales, the increase is on the order of 2,000\%. Information also suggests sale prices are considerably lower than listing prices, suggesting a marked reduction in property values despite a notable increase in property taxes in the new host neighbourhood. Unless real estate agents were well off their mark, this reduction in property values is quite significant. Other house sales in residential areas surrounding the new SAH have been followed by rezonings in support of expanded health care and related services in the neighbourhood, advancing commercial boundaries further into existing residential neighbourhoods. These trends and adverse impacts are supported by other information suggesting that a new hospital can destabilise local neighbourhoods by pressuring residents to sell and making living conditions difficult for those unwilling to leave their homes (Bailey, 2007; Beecher, 2007).

In and of itself, these changes have generated considerable transitions in the cohesion of the neighbourhood. Families directly affected by reduced home sale prices may suffer economic burdens, while families purchasing into a deflating market may find themselves in an undesirable situation. 
International Journal of Child, Youth and Family Studies (2015) 6(2): 308-327

Additionally, the co-location of the hospital with a residential neighbourhood and elementary school has heightened problems associated with drug paraphernalia, smoking in and around school property and within frequent visual range of children, trespass onto private and school properties (including reports of smokers standing in residents backyards near windows), and cases of patients in distress wandering from hospital areas (including one death in a residential backyard). These present certain risks to children's health. For example, the denormalisation of smoking is a key component of smoking reduction strategies. While the city applied these theories and practices to prohibit smoking near neighbourhood recreational facilities and the school board has policies in place that prohibit smoking on its school properties, the same cannot be said (or enforced) on public streets and trail networks. This will certainly function at odds with public health initiatives seeking to de-normalise smoking behaviour.

A strict "no smoking” policy on hospital property has prompted patients and staff to follow the path of least resistance to satisfy nicotine needs. This includes the use of a (private) forested area beside the constructed recreational trail as an ad hoc smoking area, except for those ignoring the policy at risk of enforcement, or those who trespass or use public spaces for smoking, such as the recreational trail and local neighbourhood streets. Within clear view of the school playground, this smoking area and those smokers who wander past the school on the recreational trail present a range of unhealthy messages to the children.

Finally, Official Plan Amendments are generally required for development proposals when they do not conform to the current Official Plan. In some cases, the above developments were outside the urban service boundary. As a result, such developments will levy additional expenses on taxpayers and the public in order to both provide new services and maintain various existing municipal services. Newly generated municipal tax revenues from such developments have historically not recovered their direct expenses, causing an increase in municipal taxes (Fodor, 1999). This suggests an additional levy on taxpayers, which will affect household finances, adversely affecting those most financially insecure. It will also generate a demand for services and resources that could otherwise have been directed to more urgent needs and concentrated in areas that contribute to community health and well-being.

\section{Discussion}

The World Health Organisation's Commission on the Social Determinants of Health called for Health Equity Impact Assessment of all economic agreements, market regulation, and public policies (WHO, 2008). The Senate Committee has called for Canada to adopt Health Impact Assessments of all public policies, plans, and programmes (Standing Senate Committee on Social Affairs, Science and Technology [SSCSAST], 2009). In July 2013, the Canadian Medical Association released their document, What Makes us Sick?, recommending "that the federal government require a health impact assessment as part of Cabinet decision- making process” (Canadian Medical Association [CMA], 2013).

This HIA has demonstrated the benefits for children's health and public policy from conducting such an assessment. The results of this project also demonstrate the enormous potential for local municipalities to affect the SDH, despite concerns to the contrary as expressed by municipal authorities (Collins \& Hayes, 2010) - municipal policies already exist to 
International Journal of Child, Youth and Family Studies (2015) 6(2): 308-327

adequately manage most of the identified adverse impacts. For instance, traffic calming, speed regulation, development patterns, and official plans can, and generally exist to promote healthy urban development. Noise bylaws can be structured to produce healthy urban soundscapes.

This HIA also suggests that there are additional provincial, federal, and private sector actions that could support municipalities when new health care facilities are being planned and developed. For instance, local noise bylaws would benefit from provincial and federal oversight that would equalise and standardise noise bylaws across the country. To support municipal noise bylaws and regulatory development, national noise mapping, as has been called for by the CMA, would support healthy soundscapes for children and youth. Likewise, federal actions, such as improvements to the legislation concerning heliports and, in particular, urban design and consultations, would enhance the local municipal decision-making process. At the provincial level, an HEIA of new health care facilities would fill an important gap. Furthermore, exclusion of mobile noise sources leaves a gaping hole in urban noise level management. Improved building standards, fuel efficiency, and air quality policies at federal and provincial levels can leverage best evidence for healthy environments in the same manner tobacco reduction policies have produced healthier environments for children and youth at the municipal level.

Hospitals could consider a more equitable parking fee structure that links parking fees to ability to pay using digital technologies and smart meters, and revisit the design and locating of parking lots, sound barriers, and the timing and use of equipment. The municipality could weigh the costs and benefits of locating anchor institutions outside urban boundaries, and factor in the costs of minimum parking spaces per square foot of building space in commercial, institutional, and industrial zones. Reorienting these bylaws towards maximum numbers of parking spaces and encouraging developments to incorporate transportation demand management plans would serve to expand equity of access and health-enhancing opportunities. The hospital could also revisit their strict no smoking polices in terms of societal tobacco reduction objectives and the derived impacts on the surrounding community. Local school boards could consider outdoor education programs and reclaim lost natural spaces wherever possible, working with local groups and neighbourhoods, and forming partnerships with organisations such as the SAH to identify opportunities (e.g., local gardens and food security curriculum development).

\section{Conclusions}

The new SAH in Sault Ste. Marie was constructed on a new site in the northern portion of the city. This shift has generated considerable development activity in and around the new site. That activity has become the source of numerous adverse health impacts for children. In addition, health impacts have been identified across the municipality, adversely affecting some of the most vulnerable populations including children. Existing policies and legislation to mitigate or avoid most of these adverse impacts is available. Stronger federal and provincial policies and legislation could serve to enhance municipal practices to benefit health outcomes in similar situations for improved children's health. That said, there currently remains a significant basket of tools and opportunities local municipalities can apply to enhance the social determinants of children's health. 
International Journal of Child, Youth and Family Studies (2015) 6(2): 308-327

\section{References}

Alenius, K. (2001). Consideration of health aspects in environmental impact assessments for roads. Stockholm: National Institute of Public Health, Sweden.

Bailey, M. (2007, August 7). Hospital's impact on hill debated. New Haven Independent. Retrieved from http://www.newhavenindependent.org/archives/2007/08/ynhh_hill.php.

Beecher, M. (2007, July 5). Hospital growth ignites a sell- off. Boston Globe. Retrieved from http://www.boston.com/news/local/massachusetts/articles/2007/07/05/hospital_growth_ig nites_a_sell_off/.

Berglund, B., Lindvall, T., \& Schwela, D. H. (1999). Guidelines for community noise. Geneva: World Health Organization.

Brandon, D. H. (2008). Effect of environmental changes on noise in the NICU. Advances in Neonatal Care, 8(5), S5-S10. http://dx.doi.org/10.1097/01.anc.0000337266.47599.c9

Bray, R., Vakil, C., Elliott, D., \& Abelsohn, A. (2005). Report on public health and urban sprawl in Ontario: Review of the pertinent literature. Toronto: Environmental Health Committee, Ontario College of Family Physicians.

Canadian Medical Association (CMA). (2013). What makes us sick? Ottawa: Author.

Chapman, A. (2014). The impact of reliance on private sector health services on the right to health. Health and Human Rights, 16(1), 122-133. Retrieved from http://www.hhrjournal.org/2014/07/01/the-impact-of-reliance-on-private-sector-healthservices-on-the-right-to-health/.

Children and Nature Network (CNN). (2012). Children \& nature worldwide: An exploration of children's experiences of the outdoors and nature with associated risks and benefits. Minneapolis, MN: CNN and IUCN Commission on Education and Communication. Retrieved from https://cmsdata.iucn.org/downloads/cecc_nn_worldwide_research.pdf.

Collins, P. A., \& Hayes, M. V. (2010). The role of urban municipal governments in reducing health inequities: a meta- narrative mapping analysis. International Journal for Equity in Health, 9, 13. http://dx.doi.org/10.1186/1475-9276-9-13

Correia, A. W., Peters, J. L., Levy, J. I., Melly, S., \& Dominici, F. (2013). Residential exposure to aircraft noise and hospital admissions for cardiovascular diseases: Multi- airport retrospective study. British Medical Journal, 347, f15561. http://dx.doi.org/10.1136/bmj.f5561

Dadvand, P., Sunyer, J., Basagaña, X., Ballester, F., Lertxundi, A. Fernández-Somoano, A. ... Nieuwenhuijsen, M. (2012). Surrounding greenness and pregnancy outcomes in four Spanish birth cohorts. Environmental Health Perspectives, 120(10), 1481-1487. doi:10.1289/ehp.1205244 
International Journal of Child, Youth and Family Studies (2015) 6(2): 308-327

Environmental Protection Agency. (1978). Noise: A health problem. Washington DC: Environmental Protection Agency, Office of Noise Abatement and Control.

European Agency for Safety and Health at Work (EASHW). (n.d.). What is noise? Bilbao: Author. Retrieved from https://osha.europa.eu/en/topics/noise/what_is_noise_html.

Evans, G. W. (1993). Non- auditory effects of noise on children: A critical review. Children's Environments, 10(1), 31-51.

Fodor, E., (1999). Better not bigger: How to take control of urban growth and improve your community. Gabriola Island, BC: New Society Publishers.

Frank, L. D. (2004, May). Community design and individual well being: The multiple impacts of the built environment on public health. A Narrative Presentation to the Obesity and Built Environment Conference Of the National Institute of Environmental Health Sciences, Washington, DC.

Frankenhaeuser, M. (1974). Immediate and delayed effects of noise on performance and arousal. Biological Psychology, 2(2), 127-133. http://dx.doi.org/10.1016/0301-0511(74)90020-9

Hammer, M. S, Swinburn, T. K., \& Neitzel, R. L. (2014). Environmental noise pollution in the United States: Developing an effective public health response. Environmental Health Perspectives, 122(2), 115-119. http://dx.doi.org/10.1289/ehp.1307272

Hansell A., Blangiardo, M., Fortunato, L., Floud, S., de Hoogh, K., Fecht, D., ... Elliott, P. (2013). Aircraft noise and cardiovascular disease near Heathrow airport in London: Small area study. British Medical Journal, 347, f15432. http://dx.doi.org/10.1136/bmj.f5432

Haralabidis, A., Dimakopoulou, K., Vigna- Taglianti, F., Giampaolo, M., Borgini, A., Dudley. M,-L., ... Jarup, L. (2008). Acute effects of night- time noise exposure on blood pressure in populations living near airports. European Heart Journal, 29(5), 658-664. http://dx.doi.org/10.1093/eurheartj/ehn013

Health Canada. (2005). It's your health: Community noise and annoyance (Catalogue \#,0-662- 41546- 9). Ottawa: Author.

Health Canada. (n.d.). Guidance for fine particulate matter (pm2.5) in residential indoor air. environmental and workplace health. Ottawa: Author.

Henkin R. I. (1963). Effect of sound on the hypothalamic- pituitary- adrenal axis. American Journal of Physiology, 204, 910-914.

Hoffman, B., Hennig, F., Moebus, S., Mohlenkamp, S., Dragano, J., Jakobs, H., ... Kalsch. H. (2013). Searching for the culprit: Is urban particulate air pollution or road traffic noise responsible for the association of traffic proximity with subclinical atherosclerosis? Results from the Heinz Nixdorf Recall Study. American Thoracic Society Journals, doi:10.1164/ajrccm-conference.2013.187.1_MeetingAbstracts.A3502 
International Journal of Child, Youth and Family Studies (2015) 6(2): 308-327

Holzman, D. C. (2014). Fighting noise pollution: A public health strategy. Environmental Health Perspectives, 122(2), A58. doi: 10.1289/ehp.122-A58.

Irwin K. G., Siddiqui, A., \& Hertzman, C. (2007). Early child development: A powerful equalizer. Geneva: World Health Organization. Retrieved from http://whqlibdoc.who.int/hq/2007/a91213.pdf.

Kam, P. C., Kam, A. C., \& Thompson, J. F. (1994). Noise pollution in the anaesthetic and intensive care environment. Anaesthesia, 49(11), 982-986. http://dx.doi.org/10.1111/j.1365-2044.1994.tb04319.x

Kujala, T., \& Brattico, E. (2009). Detrimental noise effects on brain’s speech functions. Biological Psycholology, 81(3), 135-143. http://dx.doi.org/10.1016/j.biopsycho.2009.03.010

Lee, M., \& Rubin, V. (2007). The impact of the built environment on community health: The state of current practice and next steps for a growing movement. Oakland, CA: Policy Link for the California Endowment.

Markevycha, I., Tieslera, C., Fuertesa, E., Romanose, M., Dadvand, P., Nieuwenhuijsenf, M., ... Heinricha, J. (2014). Access to urban green spaces and behavioural problems in children: Results from the GINIplus and LISAplus Studies. Environmental International, 71, 2935. http://dx.doi.org/10.1016/j.envint.2014.06.002

Maxwell, L. E., \& Evans, G. W. (2000). The effects of noise on pre- school children's pre- reading skills. Journal of Environmental Psychology, 20(1), 91-97. http://dx.doi.org/10.1006/jevp.1999.0144

Maybe, K., MacKinnon, B., \& Kerr, B., (2005). Evaluation of the levels of diesel-related pollutants from school buses while transporting children. Fredericton, NB: New Brunswick Lung Association.

Maynard, R., Berry, B., Flindell, I. H., Leventhall, G., Shield, B., Smith, A., Stansfield, S., \& Moorhouse, A. (Eds.). (2010). Environmental noise and health in the UK: A report by the Ad Hoc Expert Group on Noise and Health. London: Health Protection Agency.

Meerlo, P., Sgoifo, A., \& Suchecki, D. (2008). Restricted and disrupted sleep: Effects on autonomic function, neuroendocrine stress systems and stress responsivity. Sleep Medical Review, 12(3), 197-210. http://dx.doi.org/10.1016/j.smrv.2007.07.007

Milette, I. H., \& Carnevale, F. A. (2003). I'm trying to heal...noise levels in a pediatric intensive care unit. Dynamics, 14, 14-21.

Muzet A. (2002). The need for a specific noise measurement for population exposed to aircraft noise during night time. Noise Health, 4(15), 61-64.

National Collaborating Centre for Healthy Public Policy (NCCHPP). (2012). Citizen participation in health impact assessment: Overview of issues. Montreal, PQ: Author. 
International Journal of Child, Youth and Family Studies (2015) 6(2): 308-327

National Collaborating Centre for Healthy Public Policy (NCCHPP). (2014). Health impact assessment of the TOD Neighbourhood Project in Sainte-Catherine. Report on potential impacts and recommendations. Montreal, PQ: Author.

National Toxicology Program. (2010). Report on carcinogens (12th ed.). Washington, DC: Department of Health and Human Services. Retrieved from http://ntp.niehs.nih.gov/ntp/roc/twelfth/listedsubstancesreasonablyanticipated.pdf.

Noble, B. (2010). Introduction to environmental impact assessment: A guide to principles and practices. Toronto: Oxford University Press.

Nedovic, S., \& Morrissey, A.-M. (2013). Calm active and focused: Children's responses to an organic outdoor learning environment. Learning and Environmental Research, 16, 281295. http://dx.doi.org/10.1007/s10984-013-9127-9

Office of Environmental Health Hazard Assessment (OEAHA). (n.d.). Health effects of diesel exhaust. A fact sheet by Cal/EPAs Office of Environmental Health Hazard Assessment and the American Lung Association California. Sacramento, CA: Author.

Passchier-Vermeer, W., \& Passchier, W. F. (2000). Noise exposure and public health. Environmental Health Perspectives, 108(Suppl. 1), 123-131.http://dx.doi.org/10.2307/3454637

Pew Charitable Trusts. (2014). The HIA process. Philadelphia: Author. Retrieved from http://www.pewtrusts.org/en/about/news-room/news/2014/08/28/the-hia-process.

Rosenberg, J. (1991). Jets over Labrador and Quebec: Noise effects on human health. Canadian Medical Association Journal, 44(7), 869-875.

Sheer, R., \& Moss, D. (2012, September 3). Does the continued use of lead in aviation fuel endanger public health and the environment? Scientific American Earth Talk. Retrieved from http://www.scientificamerican.com/article/lead-in-aviation-fuel/

Simpson, M., \& Bruce, R. (1981). Noise in America: Extent of the noise problem (Report 550/981-101). Washington, DC: U.S. Environmental Protection Agency.

Sinclair, A., \& Diduck, A., (2009). Public participation in Canadian environmental assessment: Enduring challenges and future directions. In K. Hanna (Ed.), Evironmental impact assessment: Practice and participation (2nd ed., pp. 53-74). Don Mills, ON: Oxford University Press.

Sørensen, M., Andersen, Z., Nordsborg, R., Becker, T., Tjønneland, A., Overvad, K., \& Raaschou-Nielsen, O. (2013). Long- term exposure to road traffic noise and incident diabetes: A cohort study. Environmental Health Perspectives, 121(2), 217-222. doi:10.1289/ehp.1205503. http://dx.doi.org/10.1289/ehp.1205503 
International Journal of Child, Youth and Family Studies (2015) 6(2): 308-327

Standing Senate Committee on Social Affairs, Science and Technology (SSCSAST). (2009). A healthy productive Canada: A determinant of health approach. Final report of the Subcommittee on Population Health. Ottawa: Author.

US Green Building Council (USGBC). (2008). LEED for schools. Information Communique. Washington, DC: Author.

van den Berg, A. E., \& van den Berg, C. G. (2011). A comparison of children with ADHD in a natural and built setting. Child: Care, Health and Development, 37(3), 430-439. http://dx.doi.org/10.1111/j.1365-2214.2010.01172.x

Wachs, T. D. (1982). Early experience and human development. New York: Plenum. http://dx.doi.org/10.1007/978-1-4615-9215-0

WHO Commission on Social Determinants of Health \& World Health Organization (WHO). (2008). Closing the gap in a generation: Health equity through action on the social determinants of health. Geneva: Authors.

World Health Organization (WHO). (1999). Health impact assessment: Main concepts and suggested approach. Gothenburg Consensus Paper. Brussels: Author.

World Health Organization (WHO). (2009a). Night noise guidelines for Europe. Copenhagen, Denmark: WHO Regional Office for Europe.

World Health Organization (WHO). (2009b). Children's health and the environment: Training package for the health sector. Geneva: Author.

World Health Organization (WHO). (2011). Burden of disease from environmental noise: Quantification of healthy life years lost in Europe. Copenhagen, Denmark: WHO Regional Office for Europe.

Yang, W., \& Bradley, J. S. (2009). Effects of room acoustics on the intelligibility of speech in classrooms for young children. Journal of the Acoustical Society of America, 125(2), 922-933. http://dx.doi.org/10.1121/1.3058900 